\section{Complex clients - complex systems?}

\author{
Tania Towers \\ Senior Clinical Psychologist/Co-Ordinator Youth \\ Services \\ Next Step Specialist Drug and Alcohol Services. \\ 32 Moore Street, East Perth. Perth ,WA \\ Australia 6004
}

I would like to start with a tale...

\section{Exposure}

'Some time ago a clinical psychologist registrar noted, vexedly, that it was all very well knowing what her clients needed to do if they were to improve, but it was no use at all when they stubbornly refused to adopt or deploy such life enhancing strategies.

'Which cognitive-behavioural strategies' s/he inquired somewhat tersely and accusingly 'will fix Julia. my suicidal, selt-harming, teenager with a history of sexual abuse, dissociation, depression, drug dependence, theft, prostitution and emotional dysregulation?'

My response at the time was somewhat stilted. (In all honesty I did not like the question and the implicit claim that I was not preparing her for life as a Clinical Psychologist properly.) I said something akin to: 'Have you tried motivational interviewing, relapse prevention, problem solving, mastery and pleasure experiences, activity scheduling, self regulation exercises, self monitoring coupled with emotion and anxiety management, and, what about EMD-R?'

My response was not well received. But then I felt a bit out of my depth' (Saunders, 1998, p.16).

This tale is a true story and one that has been significant in my development as a worker in the alcohol and other drug field. At the time of completing my academic studies I thought I was more than qualified in working with young people who had alcohol and other drug problems. Not only did I have a kit bag of psychological strategies, I had been taught the add on tools that had been so thoroughly researched in the addiction's field.

However, I found that the young people I was working with were not showing a lot of improvement despite the many and varied brief interventions I tried persistently to have them employ as homework assignments. I began to think I was incompetent and at times experienced serious professional angst. At these times I thought a career change was the only option I had. In desperation, in trying to come up to scratch and look for the "magic wand' I came across a whole body of literature related to trauma that started to explain why I was experiencing so much confusion and feelings of defeat. Literature by such people as Herman (1994), Briere (1996), Linehan (1993) and Calof (1993) provided some insight as to the complexities of the role that drugs play for those with severe psychosocial difficulties.

\section{Complex Clients}

Studies of populations with substance use problems consistently report a history of abuse and neglect in childhood at much higher rates that the general population (Hernandez and Di Clemente, 1992; Abueg and Fairbank, 1992; Lisak, 1993 all cited in Van Der Kolk, 1996). This was consistent with my clinical experience.

What I found was that not only were the young people presenting with substance use problems, nor were they 'dual disorders', but if fact they could have fitted a multitude of diagnostic categories; major depression, dysthymia, anxiety disorder/s and enduring personality traits (i.e. personality disorders). The latter were extremely rigid and inflexible to change and seemed to cause them unending interpersonal problems. 
Further reading and research put a framework to what I was struggling to understand in my work with young people. Individuals who have lived through a traumatic childhood present with a great number and variety of symptoms and experience overwhelming levels of distress. The impact of trauma often comes in a 'disguised package' with chronic depression, complicate with conduct and antisocial behaviours, dissociative symptoms, impulsively, self mutilation, suicidality, somatization and anxiety. This tends to overshadow why they were referred to you initially, drug use, which is usually chaotic polydrug use.

Thus what you have is not a person with a drug problem but someone who is in immense pain in all facets of their life. There are significant difficulties present in many areas: somatic, cognitive, affective, behavioral and interpersonal (Herman, 1992).

\section{Complex Post-Traumatic Stress Disorder - A Paradigm Shift?}

A poor diagnostic concept has problems for treatment because the connection between the young person's presenting symptoms and the backdrop for their development is often forgotten. However, the difficulty is that our existing diagnostic categories do not fit the complex young people we are often trying to help.

Judith Herman (1992) addressed this in her book 'Trauma and Recovery'. According to Herman, the diagnosis of Post Traumatic Stress Disorder as we know it does not fit our client group well. Herman (1992) stated;

In general the diagnostic categories of the existing psychiatric canon are simply not designed for survivors of severe situations and do not fit them well. The persistent anxiety, phobias and panic of survivors are not the ordinary anxiety disorders. The somatic symptoms of survivors are not the ordinary psychosomatic disorders. The depression is not the same as ordinary depression and the degradation of their identity and relational life is not the same as ordinary personality disorder.

...attempts to fit the patient into the mould of existing diagnostic constructs generally. result, at best, in a partial understanding of the problem and a fragmented approach to treatment.

...even the diagnosis of 'post-traumatic stress disorder', as it is presently defined. does not fit accurately enough. The existing diagnostic criteria for this disorder are derived mainly from survivors of circumscribed traumatic events. They are based on the prototypes of combat, disaster and rape. In survivors of prolonged, repeated trauma the symptom picture is often far more complex.... survivors of abuse in childhood develop problems with relationships and identity: in addition, they are particularly vulnerable to repeated self-harm, both self inflicted and at the hands of others. The current formulation of post-traumatic stress disorder fails to capture.... the protean symptomatic manifestations of prolonged, repeated trauma.

The sindrome that follows upon prolonged, repeated trauma needs it's own name. I propose to call it complex post-traumatic stress disorder. ( p.118-119).

This is an alternative to some of the more derogatory diagnostic categories of personality disorders, which frequently instils a sense of hopelessness for mental health workers and their clients.

\section{Where do we go from here?}

Marsha Linehan (1993) in her writings on borderline personality disorder stated that working with traumatised individuals is like working with someone who has third degree burns to $80 \%$ of their body. An analogy I often remind myself on those tough days when it all seems too difficult.

There are two key concepts I believe that need to be established in working with this group of young people; creating a safe environment and developing a sound therapeutic relationship. 


\section{Safety}

Past trauma robs a young person of any sense of control and safety. Usually the traumatised young person presents with a number of strategies they have developed in order to 'cope' with negative and intense feelings resulting from past traumatic experiences. These may include suicidal behaviour, selfharming, alcohol and other drug use.

To expect a young person to cease using the only coping strategies they know, without initially building in alternative more adaptive strategies, may at best result in them being overwhelmed with emotional pain and at worst result in decompensation. Both of these states can be extremely frightening for the young person and result in relapses back to more familiar, albeit risky behaviours. This often causes the young person to feel more guilt, shame and a sense of failure.

Thus one of the first steps as a worker is to let them know you understand that the 'risky' coping strategies he/she has been using has allowed them to survive. However, given the potential risks the aim is to guide the young person into learning more functional coping strategies. Examples of these are emotion regulation and distress tolerance skills (Linehan, 1993) and these can be used by the young person to establish safety within their own bodies.

It is also important to assist the young person to achieve a safe stable living environment. It is not uncommon for this group of young people to live on the streets or in transient accommodation and have little if any financial security. Often their only social supports are like minded peers who are also struggling to survive. Family members are often not available or alternatively cause further distress and trauma for the young person. This scenario heightens the risk of further harm both physically and psychologically and provides little safety or security for the young person.

No uncovering work should be done until a young person has established a 'safe' environment both within their body and in their external environment. This initial work could range from a couple of months to many years (Herman, 1992)

\section{Therapeutic Relationship}

As stated by Herman (1992) the importance of the therapeutic relationship in developing a sense of safety cannot be overemphasised. Both the young person and the worker must build it together, often painstakingly. Trauma damages a young person's ability to enter into a trusting relationship, including the therapeutic relationship. Though the young person may have a desperate need to want to trust and rely on you as a worker s/he cannot do it because the ability to trust has often been damaged on many occasions. S/he may come in with the underlying assumption that you as a worker will eventually be unwilling or unable to help. S/he will often be ready for any sign of abandonment or rejection and may become increasingly dependent on you. As a worker impossible expectations may be requested. These are issues related to trust and not feeling safe. Be prepared for testing, possible distuption and rebuilding of the relationship.

As suggested by Linehan(1993) at times as a worker you will feel overwhelmed and helpless, underestimate your skills and knowledge and lose sight of the young person's strengths. In an attempt to deal with this you may take on the role of rescuer. This can occur in subtle 'helpful' ways such as extending appointment times or increasing their frequency, failing to explore frequent non-attendance or coming late to sessions with the client and seeing them when intoxicated. The more we do the more we are fuelling the young person's belief that s/he cannot take care of themself or accept responsibility. Other responses by workers can be to become overwhelmed by the young person's feelings of grief and anxiety, erratic moods, suicidal ideation/attempts, consequently withdrawing or avoiding the young person physically and/or psychologically. Amongst the young person's 
chaos we might forget the need to provide them with some structure and boundaries.

\section{As stated by Van der Kolk;}

..treatment often starts with prolonged negotiations centring around the issues of trust, power and safety: Often little is accomplished until a major conflict arises and is negotiated safely: Your aim is to build trust, autonomy, confidence, identity. and intimacy:(p.197)

Raphael (1998) in her discussion of what the future of Psychiatry holds, containing comments I believe can be applied to all human services. eloquently discusses the issue of the therapeutic relationship.

..the delineation of and the commitment to genuiness, empathy and warmth have been threatened in many phases of psychiatry's development; the aloofness required in some psychotherapies, the mechanisation of some behavioral therapies, dependence on diagnostic algorithms attained by strictly structured interview techniques, the reliance on psychopharmacology as the only therapeutically effective modality, threats of criticism and litigation and, now, the new accountabilities of time and money, of the rational economics of health care. Psychiatry could easily be seduced or threatened, because it is still poorly valued for it's contribution to health in general, into relinquishing its 'softer' yet most powerful contribution to human good; into failing to value this as a critical component of care, whatever the promise of new drugs, new technologies, new outcome appraisals. The costs of compassion may also be counted. Satorius has suggested burnout is one of the major issues facing human service providers in the coming century. 'Compassion fatigue' is a new catchcry. Thus retaining and incorporating compassion in new models of practice and care delivery is a particular challenge for psychiatry in the next century. (p. 749)

\section{Challenges in the field}

For me one of the greatest challenges of working with young people is not the individual psychotherapy, but the difficulties in accessing support resources and lack of inter-agency collaboration.

A recent case highlighted this for me;

Jarrod, a young twenty one year old male, was released from prison after an extended period of incarceration with no follow-up, back up support or accommodation. He had linked in well with a Psychiatrist who had visited him in prison on a regular basis and continued to maintain contact upon release. During this time she heard a history of extreme abuse and neglect.

Prior to his release he distinctly talked about his wish to straighten out his life and this meant ceasing his heroin use. He was insistent he would not return to prison. The challenges that confronted Jarrod upon being released were insurmountable and in an attempt to cope he returned to the one thing he knew to be reliable and trustworthy, i.e. heroin. The psychiatrist involved became extremely concerned about Jarrod's mental state and given the lack of safe accommodation available she thought the only option available to her to ensure his safety was to have him committed to a psychiatric hospital. However, this was fraught with practical and moral dilemmas. Firstly one had to question how damaging it would be to Jarrod to place him in this environment given he had just been released from a controlled institutional setting. Secondly, placing Jarred in a setting with psychiatrically unwell patients was not a good prospect given he did not have a psychiatric problem such as psychosis or schizophrenia. Furthermore based on past clinical experience it was assumed that soon after Jarrod was admitted he would have been discharged because it would have been said that he had an alcohol and drug problem, not a psychiatric illness.

The option of detoxification (or as I'd prefer to call it 'time out') was raised with Jarrod. 
Jarrod seemed desperate to get some help for his heroin use and appeared relieved to have a time for assessment and possible admission to the local detoxification unit. However Jarrod did not get to the unit. Another worker involved in Jarrod's case indicated that going into detox would put his probation in jeopardy because it could be used as evidence to suggest he was using. Two days later he died from an overdose.

I am not naive enough to believe that this one factor was the reason for Jarrod ending his life. He already was a troubled young boy. We will never know for sure if the overdose was intentional, as a result of his fear of returning to prison and he believed ending his life was the only option. However, what I do know is that our systems can sometimes fail the most troubled and damaged young people.

In my opinion this case was an example of how the system can retraumatise our vulnerable clients when they are viewed as 'personality disordered' and consequently 'manipulative' and 'wilful'. At times the system deals with 'bad behaviour' primarily by punishment rather than with therapy.

I am the first to acknowledge that for people like Jarrod the system only threatens to retraumatise them by placing them in an institutional setting. However, the most frustrating and tragic fact is that as workers we have so very few suitable options to ensure our marginalised and homeless young people are in fact safe - the first principle of treatment with this population.

I know we will 'lose' some but I' $m$ sure we can 'save' more if by extending our idea of harm reduction. Including models of shared care and providing better infrastructure, like long term accommodation and consistent adult supports, allows for a safe environment whilst the young person works through issues related to past trauma.

In a time of economic rationalism and deinstitutionalisation our role of creating a safe environment for traumatised young people is extremely difficult and probably the biggest challenges of my work. As stated by Ellard (1998), the philosophy of the deinstitutionalisation that is based on the notion of normalisation, was interpreted by the economic rationalists in a totally different light. Their understanding appeared to be that by reducing the number of beds in psychiatric hospitals and keeping people in the community then everything would be alright. Unfortunately a significant problem with this approach is the lack of services in the community that are available for severely traumatised young people to be kept 'safe' in the community.

\section{Conclusion}

I believe it is both a challenging and exiting time in the addictions field, particularly working with the highly at risk population of young people. There is minimal research evidence indicating best practice with this population. Up until now the majority of research has looked at brief intervention models of best practice. However, talking and listening to people in the field confirms there are a lot of workers in all disciplines who are finding things that work, despite the lack of research findings.

The difficulty is that brief interventions work for some of our population of young people but for another group of marginalised and stigmatised young people. placing them into a brief intervention program can further dismiss and reabuse them.

This population essentially needs 'rewiring' and 'reparenting' which takes flexibility, creativity, time and obviously money. I am hopeful our message will get through to those who hold the purse strings and assist us to provide safer therapeutic environments for these young people.

As stated by Achimovich (1998, p. 742) 'we first serve the patient, not the state. When we forget that, we may as well pick up our marbles and go home'. 


\section{References}

Achimovich, L. (1998). On psychiatry: some reflections circa 1998. Australian and New Zealand Journal of Psychiatry, 741-742.

Briere, J. (1996). A self-trauma model for treating adult survivors of severe child abuse, In J. Briere, L. Berliner, J.A. Bulkley, C. Jenny, T. Reid (Eds.). The APSAC handbook on child maltreatment, London : Sage.

Calof, D. and LeLoo, M. (1993). Multiple Personality and Dissociation: Understanding Incest, Abuse and MPD. USA: Parkside Publishing Corporation.

Ellard, J. (1998). On psychiatry: some reflections circa 1998. Australian and New Zealand Journal of Psychiatry, 745-746.

Herman, J. (1992). Trauma and Recovery: London: Pandora.

Linehan, M. (1993). CognitiveBehavioural Treatment of Borderline Personality Disorder. New York: Guildford Press.

Raphael, B. (1998). On psychiatry: some reflections circa 1998. Australian and New Zealand Journal of Psychiatry, 748-750.

Saunders, B. (1998). CBT and Beyond. Clinical Psychologist, 16-19.

Van Der Kolk, B. (1996). The complexity of adaptation to trauma: Self regulation, stimulus discrimination, and characterological development, In B. Van Der Kolk (Ed.). Traumatic Stress: The effects of overwhelming experience on mind, body and society. New York: Guildford Press. 